\title{
Ethmoid sinus disease and nasal septal deformities as etiologies of chronic cephalgia: Results of surgical management
}

\author{
JAMES M. REBIK, DO \\ LARRY D. MCINTIRE, DO \\ W. HADLEY HOYT III, DO \\ KENT D. MCINTIRE, DO
}

Results of a retrospective chart review of 80 patients, in conjunction with recently completed questionnaires, document the effects of sinus and nasal surgeries on chronic headache symptoms believed to originate within the ethmoid sinuses or nose. Seventy $(88 \%)$ of the patients in this study experienced a dramatic improvement of their headache symptoms after undergoing surgical treatment. The authors conclude that this type of cephalgia is more common than expected, that its cause goes largely undiagnosed by the majority of physicians, and that an effective method of treatment is available to improve the quality of life of these patients.

Of the many painful states to which humans are susceptible, headache is undoubtedly one of the most common. The causes of headache $e^{1,2}$ and facial pain ${ }^{3,4}$ are legion, and the complexity often associated with diagnosis and treatment has led to the establishment of headache clinics in many medical centers.

From the Kirksville Osteopathic Medical Center, Kirksville, Mo (Drs Rebik, L. D. McIntire, K. D. McIntire) and the Des Moines General Hospital, Des Moines, Ia (Dr Hoyt).

Reprint requests to James M. Rebik, DO, CPT, MC,Box 1415, ENT Service, Landstuhl Army Regional Medical Center, Second General Hospital, APO, NY 09180.
Headache is the seventh most frequent reason for patients to visit a physician; it accounts for about $2 \%$ of all primary care visits. ${ }^{5} \mathrm{Be}-$ tween $80 \%$ and $90 \%$ of the normal adult population report recurrent headaches, and $30 \%$ to $50 \%$ of this group characterizes the headache as severe at times or disabling. The overwhelming majority of headaches are not serious threats to health, although patients may rightfully believe otherwise until the cause is discovered. Even referral headache clinics find that only about $5 \%$ of their patients' complaints have a serious underlying cause. ${ }^{5}$

Greenfield Sluder, an American otolaryngologist who lived during the early part of this century, had a lifelong interest in headaches and neuralgias of nasal origin. He was especially interested in those headaches that he thought were caused by the closure of a sinus outlet (ostium). When this condition occurred, he believed that a vacuum was produced with subsequent negative pressure similar to that which takes place in the middle ear when the eustachian tube is blocked.

Sluder discovered that purulence was not present and transillumination of the sinuses showed no abnormality. Plain radiographic films were usually unremarkable, but on occasion a cloudiness of the affected area was present. This cloudiness disappeared when the sinus was surgically opened for ventilation. A 
majority of Sluder's cases involved the frontal sinuses, but he acknowledged that the other sinuses could be affected as well. The concept that obstruction of sinus ostia could result in absorption of atmospheric gases within the sinuses and thus produce negative pressure became a controversial subject at the time. It has since become a well-established finding. .-9 $^{-9}$

During the 1940 s, it was a widely held belief that chronic disease of the paranasal sinuses was the most common cause of cephalgia. Partly as the result of experiments conducted by McAuliffe and colleagues, ${ }^{10}$ this prevailing opinion changed. Spriggs, ${ }^{11}$ in his study of cephalgia, found that of 500 patients with a major complaint of headache, only $3 \%$ had complaints that could be attributed to chronic sinusitis. Attention then began to focus on vascular, inflammatory, emotional, and other causes, including muscle contraction, as the chief factors in the production of headaches. The theory of "vacuum headache" gradually began to fade from the literature.

With the work of Stagman ${ }^{12}$ and Shapiro ${ }^{13}$ in the 1960 s and 1970 s, interest in vacuum cephalgia and its relationship to the sphenoid sinuses and frontal sinuses was rekindled. Renewed interest also has been shown in chronic cephalgia caused by subacute sinusitis, ${ }^{14}$ nasal allergies, ${ }^{15,16}$ and nasal septal deformities. ${ }^{16-19}$ Current research pertaining to the relationship between chronic disease of the ethmoid sinuses and cephalgia remains sparse, although Sharma ${ }^{20}$ refers to it in a 1985 report.

The chronic headache pattern investigated in our study did not appear to fit into any of the more familiar recurrent headache types: migraine, cluster, tension, posttraumatic, or atypical facial pain. This type of headache has a historical pattern of frontal, retro-orbital, temporal, vertex, or maxillary pain which, in combination with the abnormal findings of the ethmoid sinuses or nose, aided in differentiating it from the other kinds of chronic headaches.

It is our objective to discuss this type of headache and to report on the various therapeutic modalities, including surgery, which were used to reduce symptoms believed attributable to chronic ethmoid sinus disease or nasal septal deformities.

\section{Materials and methods}

Between August 1978 and August 1988, 328 patientsunderwent intranasal ethmoidectomy as part of their total surgical management. Headache questionnaires were mailed to all of these patients after surgery to assess preoperative and postoperative headache parameters. Information was elicited regarding the location, quality, frequency, duration, and intensity of the headaches as well as previous modes of therapy and inciting or relieving factors. This information was added to the clinic and hospital records. Of the 328 surveys submitted, 131 (40\%) were completed and returned.

Retrospective chart review, in combination with the questionnaires, indicated that 80 patients met the preestablished study criteria. These criteria included (1) headache symptoms that did not fit into the other well-known patterns of cephalgia; (2) a history of chronic headache of at least 3 months' duration without significant response to medical management; and (3) the use of intranasal ethmoidectomy alone or with additional sinus and nasal surgeries.

The 51 patients who failed to meet the aforementioned criteria were rejected from the study for the following reasons: (1) a lack of headache or headache of less than 3 months' duration (40 patients); (2) cephalgia secondary to acute paranasal sinusitis or trauma ( $7 \mathrm{pa}$ tients); (3) extensive surgical procedures in addition to intranasal ethmoidectomy, such as maxillectomy (2 patients); and (4) deaths from other causes ( 2 patients).

The 28 male patients (35\%) and 52 female patients $(65 \%)$ who constituted the study population were between the ages of 7 and 84 years at the time of operation. A detailed headache profile form was completed for each patient evaluated for a complaint of headache (Fig 1). The examining physician performed this evaluation during the first and subsequent visits.

Next, thorough head and neck and neurologic examinations were conducted in search of potential causes of the headache. A solution 
BRIEF DESCRIPTION OF HEADACHE

\begin{tabular}{|c|c|c|}
\hline $\begin{array}{l}\text { LOCATION } \\
\square \text { Forehead } \\
\square \text { Behind the eye } \\
\square \text { Temple } \\
\square \text { Between the ey }\end{array}$ & $\begin{array}{ll}\text { Right } & \square \mathrm{I} \\
& \square \mathrm{Ch} \\
\text { e(s) } & \square \mathrm{To} \\
& \square \mathrm{Bz} \\
\text { yes } & \square \mathrm{Ne}\end{array}$ & $\begin{array}{l}\text { Left } \\
\text { neek } \\
\text { op of head } \\
\text { ack of head } \\
\text { eck }\end{array}$ \\
\hline $\begin{array}{l}\text { TYPE } \\
\square \text { Constant } \\
\square \text { Throbbing }\end{array}$ & $\begin{array}{l}\square \text { Sharp } \\
\square \text { Dull }\end{array}$ & $\begin{array}{l}\square \text { Pressure } \\
\square \text { Other }\end{array}$ \\
\hline $\begin{array}{l}\text { ONSET } \\
\square 3 \mathrm{mo}-1 \mathrm{yr} \\
\square 1.5 \mathrm{yrs}\end{array}$ & $\begin{array}{l}\square 6-10 \mathrm{yrs} \\
\square 10-20 \mathrm{yrs}\end{array}$ & $\square 20+\mathrm{yrs}$ \\
\hline $\begin{array}{l}\text { FREQUENCY } \\
\square \text { Daily } \\
\square 2-4 / \mathrm{wk}\end{array}$ & $\begin{array}{l}\square \text { Weekly } \\
\square \text { 2/month }\end{array}$ & $\begin{array}{l}\square 1 / \text { month } \\
\square<1 \text { /month }\end{array}$ \\
\hline $\begin{array}{l}\text { DURATION } \\
\square 1.4 \mathrm{hrs} \\
\square 4.8 \mathrm{hrs}\end{array}$ & $\begin{array}{l}\square 8.12 \mathrm{hrs} \\
\square 12.24 \mathrm{hrs}\end{array}$ & $\square 24+\mathrm{hrs}$ \\
\hline $\begin{array}{l}\text { IMPROVES WIT } \\
\square \text { Humidity } \\
\square \text { Sleep } \\
\square \text { Over-the- } \\
\text { counter drugs }\end{array}$ & $\begin{array}{l}\text { TH } \\
\square \text { Cocainiza } \\
\square \text { Osteopath } \\
\square \text { Other }\end{array}$ & $\begin{array}{l}\text { hic Manipulative Treatme } \\
\text { hic }\end{array}$ \\
\hline $\begin{array}{l}\text { WORSENED BY } \\
\square \text { Supine (sleepin } \\
\square \text { Smoke } \\
\square \text { Perfumes }\end{array}$ & ng) position & $\begin{array}{l}\square \text { Upper Respiratory In } \\
\text { (URI's) } \\
\square \text { Foods } \\
\square \text { Weather fronts }\end{array}$ \\
\hline $\begin{array}{l}\text { SPECIAL CHAR } \\
\square \text { Seasonal } \\
\square \text { Present upon } \\
\text { awakening }\end{array}$ & RACTERISTI & $\begin{array}{l}\text { ICS } \\
\square \text { Worse in A M } \\
\square \text { Worse in P M } \\
\square \text { Other }\end{array}$ \\
\hline
\end{tabular}

INTENSITY SCALE (10 most intense) Circle most appropriate response $\begin{array}{llllllllll}1 & 2 & 3 & 4 & 5 & 6 & 7 & 8 & 9 & 10\end{array}$

PAST THERAPY

$\begin{array}{ll}\square \text { Nasal sprays } & \square \text { Antibiotics } \\ \square \text { Antihistamine/ } & \square \text { Surgeries } \\ \text { decongestants } & \square \text { Analgesics } \\ \text { CURRENT THERAPY } & \\ \square \text { Nasal sprays } & \square \text { Antibiotics } \\ \square \text { Antihistamine/ } & \square \text { Analgesics } \\ \text { decongestants } & \end{array}$

PAST DISEASES OF SINUSES

$\square$ Allergies
$\square$ Sinusitis

CURRENT DISEASES/CONDITIONS

$\square$ Frequent URI's $\square$ Postnasal drainage

$\square$ Nasal septal deformity

$\square$ Chronic mouth breather

BEDROOM TEMPERATURE

$\begin{array}{ll}\square 55^{\circ}-60^{\circ} & \square 65^{\circ}-70^{\circ} \\ \square 60^{\circ}-65^{\circ} & \square 70^{\circ}+\end{array}$

TOBACCO USAGE

$\square$ Cigarettes (Number of packs/day

$\square$ Cigar or Pipe

PRIOR STUDIES

$\square$ Sinus X-rays

$\square$ CT scan

$\square$ Cultures

$\square$ Endoscopy

$\square$ Allergy Testing

Figure 1. Detailed headache profile form.

of $2 \%$ tetracaine/naphazoline hydrochloride $0.05 \%$ nasal spray (Pontocaine/Privine) was sprayed into the nose to provide local anesthesia and vasoconstriction of the nasal mu-

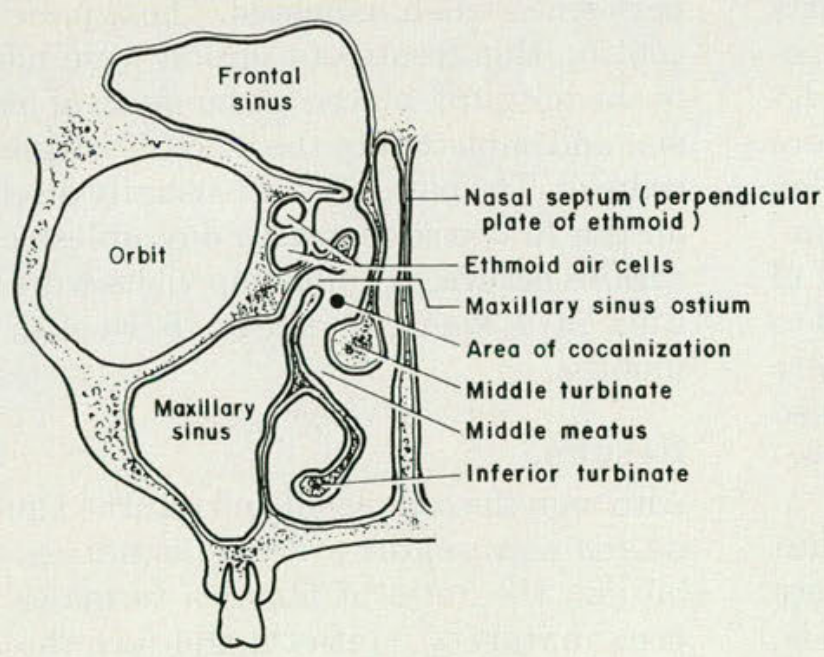

cosa and turbinates. Particularly noted were the alignment of the nasal septum; the size and appearance of the turbinates and the condition of the corresponding meatus; and the presence or absence of polypoid tissue, infection, and drainage.

The patients were initially treated conservatively with 3 months of medical management that included the use of broad-spectrum antibiotics for a minimum of 14 days, analgesics, and topical steroid nasal sprays as indicated. During the acute phases, oxymetazoline nasal spray (Afrin) was recommended for twice daily usage for

Figure 2. Coronal view of the right ostiomeatal complex indicating region of cocainization. 


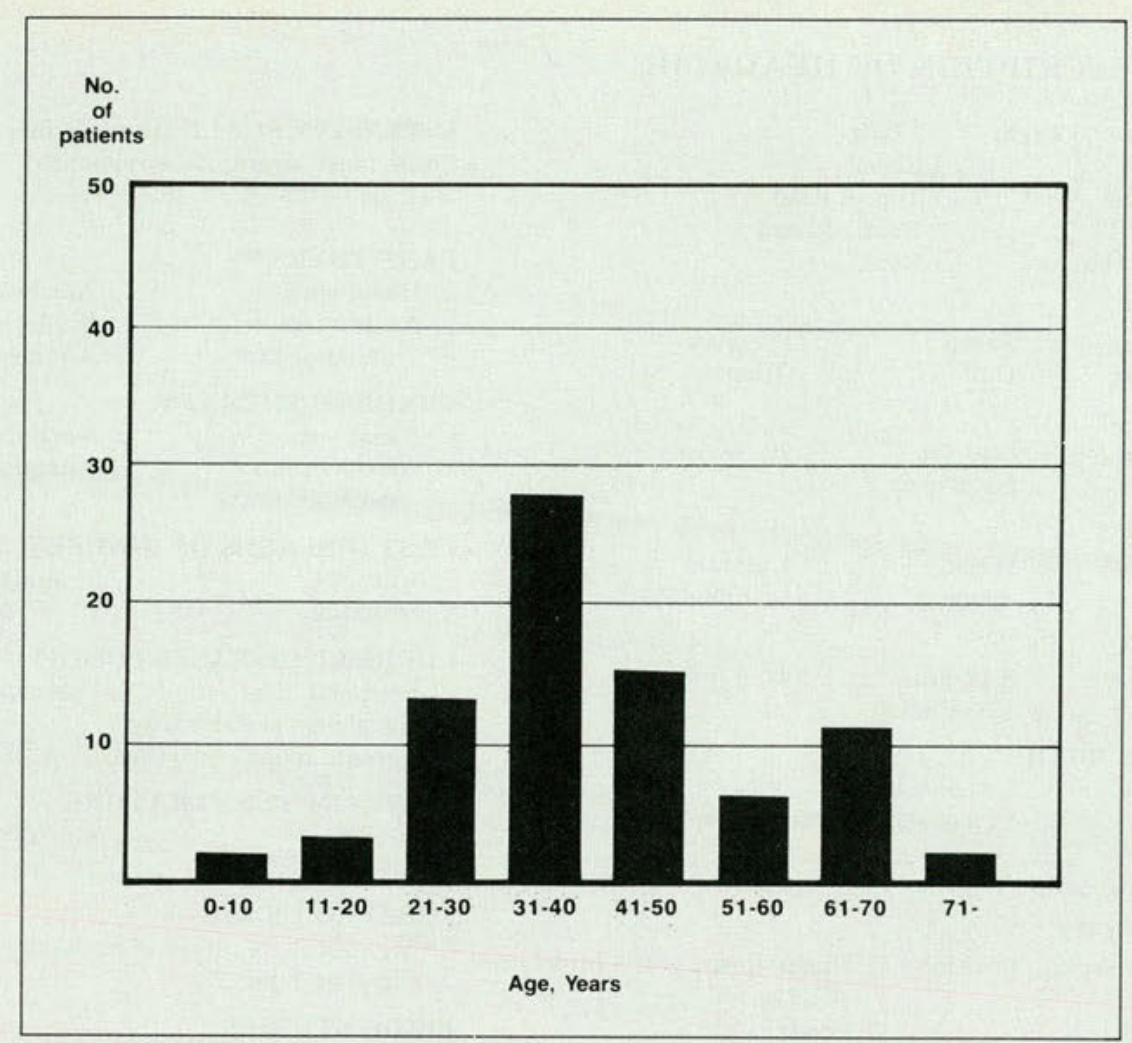

Figure 3. Age distribution of study population $(n=80)$.

4 to 5 days. Aspirin or ibuprofen-containing products (for those patients without evidence of polypoid disease), and acetaminophen were suggested for use as analgesic agents. During the period of initial workup, if it was clinically determined that the cause of a patient's headache was not related to sinus or nasal disease, the patient was appropriately referred for other treatment.

If a patient was experiencing a particularly severe episode of cephalgia and had a negative history of allergy to cocaine, cotton pledgets dipped in a $10 \%$ cocaine solution were placed adjacent to the ostiomeatal complex (Fig 2). Only the ipsilateral ostiomeatal complex was cocainized if there was a history of unilateral pain. The pledgets were allowed to remain in place for 5 to 10 minutes. They were then removed and the patient was questioned regarding the changes, if any, in the characteristics of the headache.

A review of patient records reveals that early in the study plain sinus x-ray films were used almost exclusively to aid in diagnosis. Later, computed tomography (CT) scans of the paranasal sinuses were obtained in an attempt to confirm the suspected pathology in the ethmoid or other sinuses.

Patients who continued to experience severe, recurrent symptoms following conservative medical treatment and whose symptoms improved with cocainization were offered surgical therapy in the form of intranasal ethmoidectomy with additional surgical procedures performed when indicated. Those patients accepting this treatment option were admitted to the hospital, placed under general anesthesia, and subjected to the elective surgical procedures. The patients were usually discharged on the first postoperative day unless complications occurred. Follow-up visits were scheduled at 1 week, 3 weeks, 8 weeks, and 6 months.

\section{Results}

Although the completed and returned questionnaires represented a nearly equal sex distribution, the ratio of females to males of approximately $2: 1$ reflects the fact that more women than men met the established criteria. 


\begin{tabular}{|c|c|c|c|c|}
\hline \multicolumn{5}{|c|}{$\begin{array}{c}\text { Table } 1 \\
\text { Frequency of Headaches }(n=80)\end{array}$} \\
\hline \multirow[b]{2}{*}{ Frequency } & \multirow{2}{*}{\multicolumn{2}{|c|}{ Preoperatively }} & \multirow{2}{*}{\multicolumn{2}{|c|}{$\begin{array}{l}\text { Postoperatively } \\
\text { No. }(\%)\end{array}$}} \\
\hline & & & & \\
\hline Daily & 40 & (50) & 7 & ( 9 ) \\
\hline 2 to $4 / \mathrm{wk}$ & 8 & (10) & 5 & ( 6$)$ \\
\hline Weekly & 13 & (16) & 12 & (15) \\
\hline $2 / \mathrm{mo}$ & 1 & (1) & 5 & ( 6$)$ \\
\hline $1 / \mathrm{mo}$ & 1 & ( 1$)$ & 3 & ( 4$)$ \\
\hline$<1 / \mathrm{mo}$ & 0 & $(0)$ & 34 & $(42)$ \\
\hline $\begin{array}{c}\text { Nonspecific } \\
\text { response }\end{array}$ & 17 & (22) & 14 & (18) \\
\hline
\end{tabular}

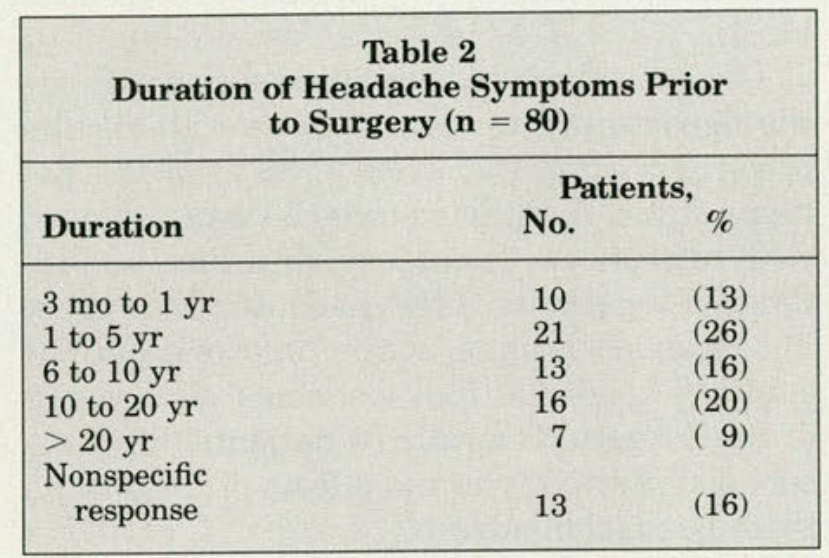

All age groups showed a nearly equal sex distribution, except for the female preponderance in the 31- to 40 -year age group (19 of 28 patients, [68\%]) and the 51- to 60-year age group (5 of 6 patients [80\%]) (Fig 3). In their responses to the initial headache profile form or the questionnaire, very few of the patients were able to localize the area of headache to one specific anatomic site. The majority of patients indicated two or more anatomic locations. The preoperative localization of the headache as reported by the patients was as follows: frontal, 46 patients (58\%); retro-orbital, 37 patients $(46 \%)$; temporal, 25 patients $(31 \%)$; vertex, 11 patients (14\%); occipital or maxillary, 4 patients (5\%); cervical, 2 patients (3\%); and nonspecific or the entire head, 15 patients $(19 \%)$. When the subjects attempted to describe the quality of pain experienced, they were again unable to limit their answers to one response. The two pain qualities most often cited were constant (44 patients [55\%]) and throbbing (27 patients [34\%]); sharp and dull were
Table 3

Duration of Headache $(n=80)$

\begin{tabular}{|c|c|c|c|c|}
\hline \multirow[b]{2}{*}{ Duration } & \multicolumn{2}{|c|}{ Preoperatively } & \multicolumn{2}{|c|}{ Postoperatively } \\
\hline & No. & $(\%)$ & No. & $(\%)$ \\
\hline $1 \mathrm{hr}$ & 0 & $(0)$ & 29 & (36) \\
\hline 1 to $2 \mathrm{hr}$ & 5 & ( 6$)$ & 4 & ( 5$)$ \\
\hline 2 to $4 \mathrm{hr}$ & 5 & ( 6$)$ & 4 & ( 5$)$ \\
\hline 4 to $6 \mathrm{hr}$ & 3 & (4) & 3 & $(4)$ \\
\hline 6 to $8 \mathrm{hr}$ & 2 & ( 3 ) & 1 & $(1)$ \\
\hline $8 \mathrm{hr}$ to days & 33 & (41) & 6 & $(8)$ \\
\hline $\begin{array}{c}\text { Nonspecific } \\
\text { response }\end{array}$ & 32 & $(40)$ & 33 & $(41)$ \\
\hline
\end{tabular}

\begin{tabular}{|lrc|}
\hline \multicolumn{3}{|c|}{ Table 4 } \\
Radiologic* Findings $(n=80)$ \\
\hline Finding & No. & $\%$ \\
\hline Unremarkable & 39 & $(49)$ \\
Chronic ethmoid sinusitis & 10 & $(13)$ \\
Chronic maxillary sinusitis, polyps & 26 & $(33)$ \\
Chronic sphenoid sinusitis & 3 & $(4)$ \\
Chronic frontal sinusitis & 3 & $(4)$ \\
Pansinusitis & 4 & $(5)$ \\
& *Plain sinus x-ray films or CT scans of the paranasal sinuses. \\
Some patients had more than one finding. \\
\hline
\end{tabular}

mentioned by 19 patients $(24 \%)$ and 18 patients $(23 \%)$, respectively.

Preoperative and postoperative headache frequencies are shown in Table 1. Before surgery, $40(50 \%)$ of the patients were experiencing a daily headache. After surgery, only $7(9 \%)$ of the patients reported a similar frequency. None of the patients stated preoperatively that their headache occurred less than once each month. After surgery, $34(42 \%)$ of the patients indicated their headache to be of this frequency. Before surgery, symptoms persisted from 3 months to more than 20 years (Table 2).

Table 3 shows the duration of headache in hours. Thirty-three (41\%) of the patients stated prior to surgery that their headaches lasted 8 hours or longer; after surgery only six patients reported headaches of this duration. A dramatic reduction in headache duration to 1 hour or less was noted in 29 (36\%) of the patients.

Each patient was asked to quantify the intensity of the headache on a scale of 0 to 10 , 
Table 5

Major Types of Surgery Performed $(n=80)$

\begin{tabular}{|c|c|c|}
\hline Surgical procedure & No. & $\%$ \\
\hline \multicolumn{3}{|l|}{$\begin{array}{l}\text { Ethmoidectomy* and maxillary } \\
\text { antrostomy, bilateral with } \\
\text { septoplasty }\end{array}$} \\
\hline $\begin{array}{l}\text { Ethmoidectomy, unilateral or } \\
\text { bilateral with septoplasty }\end{array}$ & 18 & \\
\hline Ethmoidectomy and maxillary & 10 & (20) \\
\hline antrostomy, bilateral & 14 & (18) \\
\hline Ethmoidectomy, unilateral & 4 & $(5)$ \\
\hline Ethmoidectomy, bilateral & 3 & $(4)$ \\
\hline \multicolumn{3}{|l|}{$\begin{array}{l}\text { Additional nasal } \\
\text { sinus procedures } \\
\qquad(\mathbf{n}=80)\end{array}$} \\
\hline None & 28 & (35) \\
\hline Sphenoidotomy & 20 & (25) \\
\hline Partial turbinectomy & 15 & (19) \\
\hline Polypectomy & 10 & (13) \\
\hline \multicolumn{3}{|l|}{$\begin{array}{l}\text { Caldwell-Luc operation on } \\
\text { the maxillary sinus }\end{array}$} \\
\hline
\end{tabular}

with 0 representing no headache and 10 representing the most severe headache. The range of responses preoperatively was 2 to 10 , with the average measure of intensity being 8.3 . Postoperatively, the average measure fell to 5.2 (range 1 to 10 ).

Sixty-nine $(86 \%)$ of the patients had sought the aid of other physicians for their headache prior to physician-referral or self-referral to us. Previous medical therapy included those management strategies already mentioned as well as immunotherapy in $15 \%$ of the patients.

The three major factors that exacerbated the headache symptoms were, in decreasing frequency, smoke (35\%), perfume (20\%), and meteorologic changes $(15 \%)$. Other factors mentioned were seasonal or inhalant allergies, stress, and the prone position. Nasal sprays, rest, and increasing the humidity of inspired air were the most helpful measures reported by the patients.

When chronic sinus disease was considered a potential factor, part of the headache workup included acquiring plain sinus $\mathrm{x}$-ray films or CT scans of the paranasal sinuses. Nearly half of these imaging modality studies failed to re-
Table 6

Length of Postoperative Follow-up $(n=80)$

\begin{tabular}{|lll|}
\hline $\begin{array}{l}\text { Length of } \\
\text { follow-up }\end{array}$ & \multicolumn{2}{c|}{ Patients, } \\
No. & $\%$ \\
\hline 2 mo to 1 yr & 24 & $(30)$ \\
1 to 2 yr & 14 & $(18)$ \\
3 to 4 yr & 24 & $(30)$ \\
5 to 10 yr & 18 & $(22)$ \\
\hline
\end{tabular}

veal the presence of any disease process (Table 4).

The questionnaires also allowed the patients the opportunity to assess the overall results of surgery (Fig 4). Seventy $(88 \%)$ of the patients stated that their headache was improved with reference to frequency, duration, and intensity; 9 patients (11\%) indicated that there had been no change, while only one patient said his headache had worsened as a result of the surgery. Overall, 70 patients $(88 \%)$ responded positively to the effects of surgery on their headache pattern.

The types of surgeries performed are shown in Table 5. Forty patients in this study underwent bilateral intranasal ethmoidectomies and maxillary antrostomies with nasal septal reconstruction. The procedure common to all of the patients was the intranasal ethmoidectomy; 58 patients ( $73 \%$ ) also underwent septoplasty. The nasal and sinus procedures listed at the bottom of Table 5 were performed only when abnormal physical or radiologic findings were discovered. These additional procedures included sphenoidotomy, partial inferior or middle turbinectomy, polypectomy, or a CaldwellLuc operation on the maxillary sinus.

The postoperative follow-up time is shown in Table 6 . Of the 56 patients having a followup time of 1 year or longer, $50(89 \%)$ have reported a dramatic improvement of symptoms since surgery. Of the 18 patients who have now been followed up from 5 to 10 years after surgery, $15(83 \%)$ report similar improvement.

There were 149 ethmoidectomies performed in these 80 patients with four complications occurring in four patients. The postoperative complication rate was $2.7 \%$, which included 
three episodes of epistaxis (2\%) and one cerebrospinal fluid leak $(0.7 \%)$.

\section{Discussion}

A diagnosis of recurrent headache secondary to ethmoid sinus disease or nasal septal deformities may initially appear to be a diagnosis of exclusion. This is not surprising when one considers that more than $85 \%$ of our patient population had been treated by physicians representing allergy/immunology, general practice, internal medicine, neurology, osteopathic manipulative treatment, otolaryngology, or psychiatry. At first glance, the nearly $2: 1$ female-to-male sex ratio may seem to imply an unreliable patient sample. However, women suffer disproportionately from chronic headache symptoms in general, and the reported prevalence in women can be as high as two to three times that of men. ${ }^{20}$

The majority of these patients' inability to localize the headache area to one specific anatomic site appears to reflect one of the characteristics common to this type of chronic headache. Most frequently patients reported pain in the frontal $(58 \%)$, retro-orbital $(46 \%)$, and temporal $(31 \%)$ areas. This response would suggest that either a single causal site exists with the subsequent widespread referral of pain, or that multiple sites contribute to this chronic pain pattern.

McAuliffe and coworkers ${ }^{10}$ were able to map areas of the head and neck to which pain was referred after direct stimulation of the septum, turbinates, and sinus ostia by noxious stimuli. They discovered that stimulation of the maxillary sinus ostia and turbinates produced the highest pain intensity levels.

The data in Table 1, comparing preoperative and postoperative headache frequencies experienced by this patient population, indicate that surgery effected a decrease in headache frequency.

The headache symptoms investigated in this study had been present in these patients from 3 months to 35 years. Sixty-nine $(87 \%)$ of these patients said that their symptoms had been present for longer than 1 year (Table 2).

Headache duration before and after surgery is shown in Table 3 . The findings suggest that

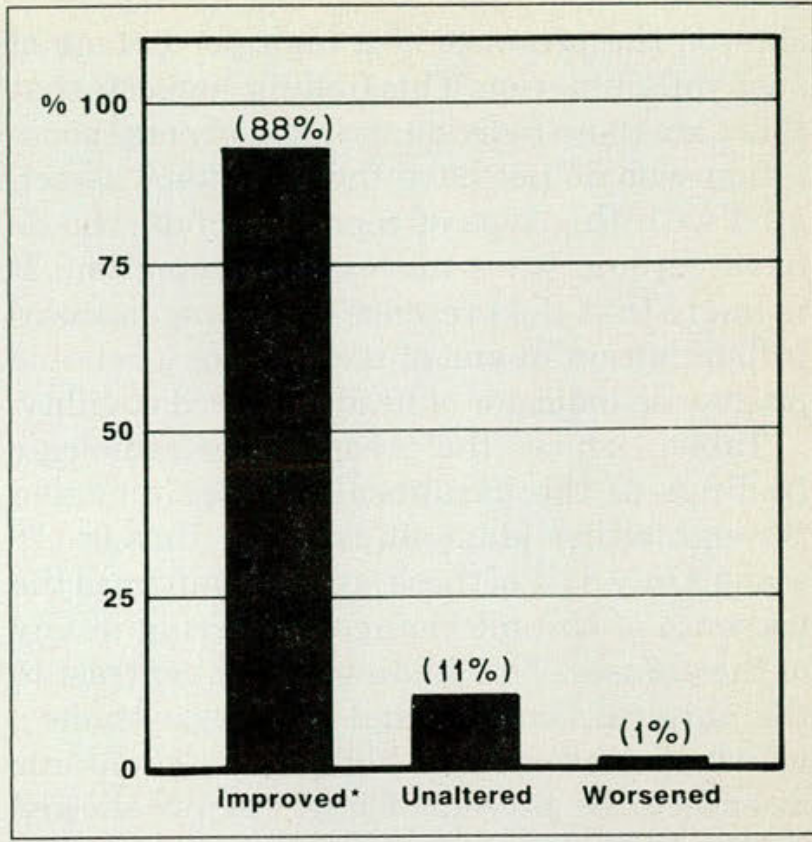

Figure 4. Study population's assessment of overall results of surgery. ( *ndicates decrease in all of the following variables: frequency, duration, and intensity.)

surgery had a beneficial role in reducing the duration of headache symptoms.

The most subjective response elicited by patient histories involved the perceived intensities of their headaches. Currently, no available standardized method exists for comparing pain intensities among individual patients. One patient's perception of headache pain and its intensity may be quite different from that of another patient. However, these patients as a whole did report a reduction in their headache intensity after surgery.

The presence of tobacco smoke and perfumes and changes in weather patterns were the exogenous factors most commonly identified as stimuli that initiated the headache, prolonged its duration, or increased its intensity. The most common medical therapeutic options used to improve the patients' symptoms included nasal sprays, bedrest, and increasing the humidity in the environment. A review of the pathologic findings of those patients who met the study criteria showed a very high percentage of chronic mucosal inflammation to be present.

A review of the pathologic findings of those patients not meeting the study criteria also 
showed the presence of a high percentage of such inflammation. This finding suggests that there are those individuals in the general population who do not have the symptoms associated with this type of cephalgia, but who do have chronic sinus mucosa inflammation. It is likely that the presence of chronic mucosal inflammation in and of itself is not a reliable prognostic indicator of headache predictability.

Table 4 shows the preoperative radiologic findings of the paranasal sinuses revealed through either plain sinus x-ray films or CT scans. Only $51 \%$ of these studies confirmed the presence of chronic changes occurring in any of the sinuses. This finding was in contrast to the surgical findings and histologic studies, which showed a much higher rate of chronic disease to be present. Chart review showed that a large number of patients who underwent surgery 5 to 10 years earlier did not have preoperative CT scans performed because only plain x-ray diagnosis was available to the authors at that time. Because the plain sinus $\mathrm{x}$-ray films largely lacked diagnostic acuity in revealing chronic sinus disease, the decision to operate on the ethmoid sinuses was largely based on the patient's history and response to cocainization of the appropriate ostiomeatal complex.

As it became apparent that plain x-ray films did not reveal the abnormalities discovered at surgery, CT scans replaced the plain x-ray procedure in the preoperative evaluation of these patients. Subtle changes of the ethmoid sinuses and ostiomeatal complex seen on the CT scans correlated with intraoperative findings. This correlation led to an increase in the authors' preoperative diagnostic ability regarding positive radiologic findings. It is imperative that the radiologist interpreting the scans also becomes knowledgeable regarding the subtle visual pathologic changes occurring in the ethmoid labyrinth and ostiomeatal complex.

The types of surgical procedures used in the treatment of our patient population are shown in Table 5. Fifty percent of the patients underwent bilateral intranasal ethmoidectomies and maxillary antrostomies with septoplasty. All patients underwent intranasal ethmoidectomy, which was done in an effort to surgi- cally remove suspected chronically inflamed and hyperplastic sinus mucosa as well as to provide ventilation to these sinuses. Maxillary antrostomies were performed when the patient complained of maxillary pressure or nonspecific pain. If the radiologic studies revealed large polyps present in the maxillary sinuses, a Caldwell-Luc operation was performed.

Nearly three fourths of the patients had a nasal septal deformity that significantly impaired adequate nasal ventilation. In these patients, a septoplasty was also performed. Eighteen percent of the patients underwent bilateral intranasal ethmoidectomies and maxillary antrostomies, while $9 \%$ had only unilateral or bilateral ethmoidectomies performed.

The effects of these types of surgical procedures on the patients' headache patterns is shown in Figure 4 . Seventy patients $(88 \%)$ reported an improvement in their symptoms reflected as a decrease in headache frequency, duration, and intensity. These patients were not entirely "cured" of their headaches, but they experienced a significant improvement in the quality of life as compared with their preoperative condition. Nine patients $(11 \%)$ reported no change in their headaches after surgery, and one patient said that his headaches had worsened.

Data analysis shows that the positive response to surgery was not based on age or gender alone, although five (18\%) of the male patients indicated that their headache symptoms were unaltered as compared with only three $(6 \%)$ of the female patients.

Among this study group, 56 patients have been followed up for 1 year or more postoperatively (Table 6). Of these patients, $50(89 \%)$ have reported a dramatic improvement of their headaches after treatment. Although only 18 patients have been followed up longer than 5 years, $15(83 \%)$ of them revealed a similar improvement.

The postoperative complication rate was $2.7 \%$, which is similar to that for intranasal ethmoidectomy procedures reported elsewhere. $^{21}$

Initial attempts at studying the architecture of the ethmoid sinuses can result in frustration and confusion (Fig 2). The honeycomb ap- 
pearance of these cells conveys the impression of a hopeless entanglement put together without apparent regard to order. They have been described numerous times as a "labyrinth." However, when studied individually, these cells were found to be readily identified and separated into groups, with each group having a distinct area of drainage into the nose and having no communication with cells of an adjacent group. On an individual basis, the ethmoid sinuses are found to be no more variable than the other sets of paranasal sinuses.

A single ethmoid labyrinth may possess two to eight anterior and middle cells and one to eight posterior cells. ${ }^{22}$ These thin-walled cells have an approximate total volume of $8 \mathrm{~mL}$ to $10 \mathrm{~mL}$ per side. The middle turbinate is often pneumatized by either anterior or posterior cells, and removal of these middle turbinate cells (concha bullosa) may be important in the eradication of chronic ethmoid sinus disease. ${ }^{23}$

The ostia of the ethmoid cells measure $1 \mathrm{~mm}$ to $2 \mathrm{~mm}$ in diameter and are the smallest of the paranasal sinus ostia. These ostia are lined with mucoperiostium and have no muscular attachments. Therefore, a mechanism for actively ventilating the sinuses, as is found in a normally functioning eustachian tube and middle ear, is not present. ${ }^{9}$

The ethmoid sinuses are lined by pseudostratified ciliated columnar epithelium that is $25 \mu$ to $45 \mu$ in thickness. The ciliated cells outnumber the mucus-secreting goblet cells by a ratio of $4: 1 .^{24}$ Seromucinous glands are present in all sinus parts, with the greatest concentration near the ostia. However, the density of this particular gland is 15 times less than it is in the nose. This fact explains the minimal ability of the sinuses to produce mucus when compared with that of the nose. ${ }^{25,26}$ Ciliary motion toward the ostia aids the mucous flow. This action makes the sinuses normally self-cleaning. ${ }^{25,26}$

The principal components of the nasal septum are the vomer and perpendicular plate of the ethmoid posteriorly with the quadrilateral cartilage occupying the anterior portion. The septum is covered predominantly by respiratory mucosa.

Opposite the nasal septum is the lateral

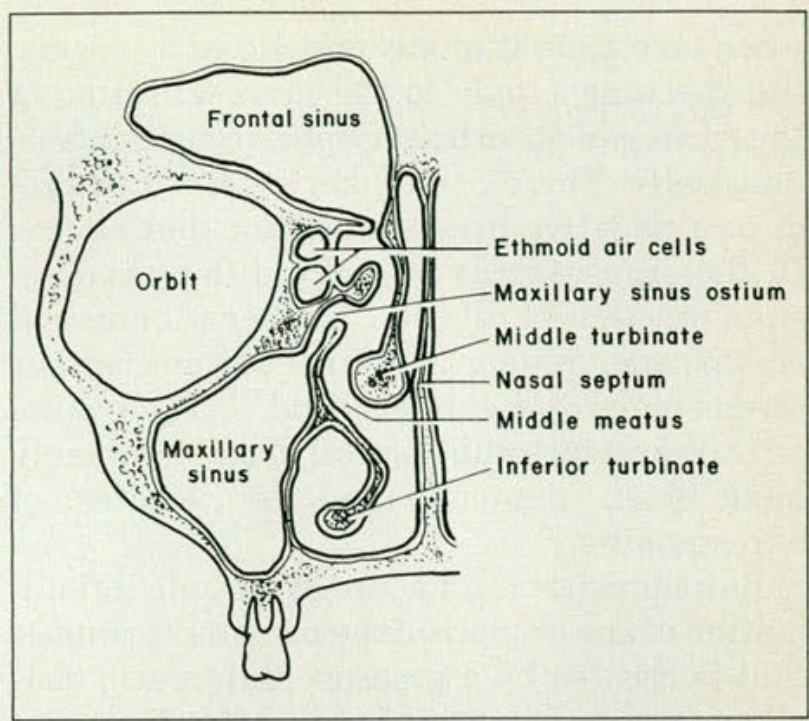

Figure 5. Septal deformity in which nasal septum contacts lateral wall of nose.

wall of the nose. This is a complex anatomic area, but it consists primarily of the turbinates, their respective meatus, and the openings of the paranasal sinuses and the nasolacrimal duct. Several branches of the ophthalmic and maxillary divisions of the trigeminal nerve provide sensory innervation to the nasal septum, the lateral wall of the nose, and the ethmoid labyrinths. It is this area of sensory innervation near the ostiomeatal complex that is of interest to the examining physician during the placement of cocaine-impregnated cotton pledgets.

The nasal septum can be subjected to traumatic influences acquired prenatally, during the birth process itself, or at any time into adulthood. It is possible for the septal deformity to be of such a degree as to cause direct contact with the lateral wall of the nose (Fig 5). This contact can be intermittent, occurring when the parasympathetic system is activated. It may also be continuous when a septal deformity and enlarged turbinate press against each other.

Several factors can cause ostial occlusion that could contribute to ostial narrowing by increasing mucosal edema near the sinus openings. These factors include chemical irritants, hyperplastic sinusitis (with or without polyp formation), anatomic deformities, and, less commonly, neoplasms. ${ }^{9}$ As previously mentioned, 
when an ostium is totally obstructed by edema, the vascular supply to the mucosal lining of the sinus can absorb atmospheric gases transmucosally. These atmospheric gases can produce a negative pressure within that cavity. In the sinuses, this pressure differential results in vascular dilation, further submucosal edema, and, frequently, transudation of either serous or serosanguinous fluid. ${ }^{7,8}$ The results of this pressure differential most commonly have been demonstrated by studies of barosinusitis.

Barosinusitis is an acute or chronic inflammation of one or more of the paranasal sinuses that is created by a pressure difference, usually negative, between the air in the sinus and that of the surrounding atmosphere. Ordinarily, this relative negative pressure in the sinus will cause a space-filling phenomenon manifested as edema of the mucous membrane or transudation of serous fluid into the sinus, thus permitting equalization of the pressure difference.

Barosinusitis symptoms range from a mild feeling of fullness, to sudden, incapacitating pain thought to be produced by blood accumulating beneath the submucosal layer and pushing the epithelium away from the bony walls. Resolution usually occurs from within a few hours to several days. The more severe cases persist for as long as a few weeks. While the existence of barosinusitis cannot be used literally to confirm the vacuum headache defined by Sluder or the chronic cephalgia described here, the clinical and radiologic presentation of mild forms of barosinusitis do resemble certain aspects of these headache types.

An extensive search of the literature failed to reveal published studies in which actual pressure changes have been measured in the ethmoid air cells themselves. However, in the studies conducted, functional tests of the maxillary ostia ${ }^{27}$ have been done or pressure changes of the maxillary sinuse ${ }^{28}$ have been assessed.

Several years ago, two of the authors (L.D.M., W.H.H.) attempted to directly measure pressure changes within the ethmoid sinuses in human volunteers who were undergoing elective ethmoid sinus surgery and who agreed to be a part of that study. The ethmoid air cells were trephined with an 18-gauge spinal needle attached to plastic intravenous tubing and a fluid media transducer. This transducer was connected to a model 5 Grass polygraph that had been calibrated to atmospheric pressure. In each subject, several different air cells or group of cells were trephined in the ethmoid labyrinth. Following this procedure, exenteration of the ethmoid labyrinth was completed. The results of this limited study were inconclusive in determining whether or not a correlation existed between the headache pain pattern and positive or negative pressure changes in the ethmoid cells.

The authors acknowledge that the overwhelming majority of patients who experience upper respiratory tract infections and symptoms attributable to diverse airborne irritants, as well as others who have intranasal polypoid disease or a deviated nasal septum, do not experience cephalgia secondary to these chronic disease processes. Yet there exists a minority of patients who do have headache patterns that we believe are caused by changes that occur within the ethmoid sinuses or as a result of abnormalities of the nasal septum or turbinates. It is for these patients that this method of treatment is offered. It should be noted, however, that the treatment is offered only after the physician completes an extensive history complemented by a meticulous physical examination that includes application of topical anesthetic agents and CT documentation.

Not everyone believes that recurrent headaches can be initiated or exacerbated by chronic sinus disease. In fact, some studies ${ }^{2}$ minimize or do not even mention this possibility. The likelihood of chronic headache patterns being initiated or perpetuated by longstanding sinus disease is an idea that leading endoscopic surgeons are slowly, almost cautiously, bringing forward. ${ }^{29}$ This controversy continues to draw heated debates among otolaryngologists, neurologists, and others who manage complicated headache patients.

A need exists for further innovative research in this challenging area of medicine. The authors are aware of the potential inher- 
ent shortcomings of a retrospective study without controls and of the possibility of drawing inappropriate conclusions from the data involved. We have subsequently designed a randomized, prospective study that is currently being conducted in an attempt to further elicit the contributions of sinus disease to certain headache patterns.

\section{Conclusion}

We have reviewed 80 cases of chronic cephalgia believed to originate within the ethmoid sinuses or nose and have reported the effects of surgical treatment on these headaches. Eighty-eight percent of these patients experienced a dramatic improvement after undergoing intranasal ethmoidectomy in combination with nasal or sinus procedures.

For carefully selected patients, it appears that enlargement of the ostia with exenteration of diseased tissue of the ethmoid air cells and correction of nasal septal deformities results in a significant improvement of headache symptoms. Chronic sinus disease and nasal septal deformities should be included in the differential diagnosis of headache patients who do not fit the other well-known patterns of chronic cephalgia.

The authors would like to thank Mrs Carla True for her assistance in preparing this manuscript.

1. Grubbs SS, Keating JH III, Gersch DB: Medical grand rounds: A patient with 'Ferocious' headache. Del Med J 1986;58:719-730.

2. Joseph DJ, Renner G: Head pain from diseases of the ear, nose, and throat. Neurol Clin 1983;1:399-414.

3. Miller H: Pain in the face. Br Med $J$ 1968;2:577-580.

4. Drinnan AJ: Differential diagnosis of orofacial pain. Dent Clin North Am 1978;22:73-87.

5. Gordon B, Barker LR, Bleeker ML: Headache and facial pain, in Barker LR (ed): Principles of Ambulatory Medicine, ed 3. Baltimore, Williams \& Wilkins, 1986, pp 1119-1133.

6. Hanna HH, Yarington CT, Jr: Otolaryngology in aerospace medicine, in DeHart RI (ed): Fundamentals of Aerospace Medicine. Philadelphia, Lea \& Febiger, 1985, pp 511-537.

7. Hanna HH: Aeromedical aspects of otolaryngology. Aviat Space Environ Med 1979;50:280-283.

8. Love JT Jr, Caruso VG: Civilian air travel and the otolaryngologist. Laryngoscope 1978;88:1732-1742.
9. Stewart TW Jr: Common otolaryngologic problems of flying. Am Fam Physician 1979;10:113-119.

10. McAuliffe GW, Goodell H, Wolff HG: Experimental studies on headache: Pain from the nasal and paranasal structures. Proc Assn Res Nerv Ment Dis 1942;23:185-208.

11. Spriggs E: The clinical study of headache (Croonian lecture). Lancet 1935;2:1-8.

12. Stagman J: Sphenoid vacuum cephalgia. Headache 1967;7:30-32.

13. Shapiro SL: Vacuum headache. Eye Ear Nose Throat Monthly 1970;49:414-417.

14. Faleck H, Rothner AD, Erenberg G: Headache and subacute sinusitis in children and adolescents. Headache 1988;28:96-98. 15. Moore GF, Massey JD, Emanuel JM: Head pain secondary to nasal allergies. Ear Nose Throat $J$ 1987;66:502-511.

16. Hoover S: The nasal patho-physiology of headaches and migraines: Diagnosis and treatment of the allergy, infection, and nasal septal spurs that cause them. Rhinology 1987; suppl 2, pp 3-23.

17. Chiancone G: With chronic headache, the diagnosis may be right under your nose (letter). Va Med J 1988;115:150.

18. Gerbe RW, Fry TL, Fischer ND: Headache of nasal septal spur origin: An easily diagnosed and surgically correctable cause of facial pain. Headache 1984;24:329-330.

19. Schonsted-Medsen U, Stoksted P, Christensen PH, et al: Chronic headache related to nasal obstruction. J Laryngol Otol 1986;100:165-170.

20. Sharma GK: The role of ethmoid and middle turbinate surgery in patients with chronic headache. Indian $J$ Otolaryngol $1985 ; 37: 36-37$

21. Freidman HM, Kern EB: Complications of intranasal ethmoidectomy: A review of 1000 consecutive operations. Laryngoscope 1979;89:421-434.

22. Graney DO: Anatomy (Paranasal sinuses), in Cummings CW et al (ed): Otolaryngology-Head and Neck Surgery. St. Louis, CV Mosby Co, 1986, vol 1, pp 842-849.

23. Friedman WH, et al: Sphenoethmoidectomy: The case for ethmoid marsupialization. Laryngoscope 1986;96:473-479.

24. Tos M, Mogensen C, Novotny Z: Quantitative histology of the normal ethmoidal sinus. Otorhinolaryngol 1978;40:172-180.

25. Ballenger JJ: The clinical anatomy and physiology of the nose and accessory sinuses, in Ballenger JJ (ed): Diseases of the Nose, Throat, and Ear, ed 12. Philadelphia, Lea \& Febiger, 1977, pp 10-11.

26. Taylor M: Physiology of the nose, paranasal sinuses, and nasopharynx, in English GM (ed): Otolaryngology. Hagerstown; Harper \& Row, 1980, vol 2 (revised), pp 1-40.

27. Rantanen T: Clinical function tests of the maxillary sinus ostium. Acta Otolaryngol 1974;328(suppl):1-38.

28. Drettner B: Pressure readings in the maxillary sinus. Int Rhinol 1965;3:313-318.

29. Stammberger $\mathrm{H}$, Wolf G: Headaches and sinus disease: The endoscopic approach. Ann Otol Rhinol Laryngol 1988;97(suppl 134, pt 2):3-23.

Raskin NH, Appenzeller O: Headache. Philadelphia, WB Saunders Co, 1980 .

Sluder G: Nasal Neurology, Headaches, and Eye Disorders. St. Louis, CV Mosby Co, 1927. 


\section{The most important thing you can take to}

the 95th annual convention and scientific seminar of the American Osteopathic Association.

November 25-29, 1990

It's United-the airline saving you real money to the American Osteopathic Association Convention in Las Vegas.

United and United Express now offer special Meeting Plus ${ }^{\mathrm{TM}}$ savings. That means $45 \%$ off regular coach fares. Plus something really unconventional: no minimum length of stay.

Or, if you prefer, we'll give you an additional $5 \%$ off our already low discounted fares, provided you meet the requirements. That could save you as much as $70 \%$ off regular coach fares.

Convening was never this convenient before.

Of course, you'll only be able to get these low fares for travel between $11 / 23-12 / 2 / 90$. All you have to do is provide us with your group's Meeting Plus ${ }^{\mathrm{TM}}$ ID number: $0150 \mathrm{~J}$

For reservations, call the United Meetings Plus ${ }^{\text {TM }}$ Desk at 1-800-521-4041. We're open seven days a week from 8 a.m. to 11 p.m. (EST.)

Come fly the friendly skies.
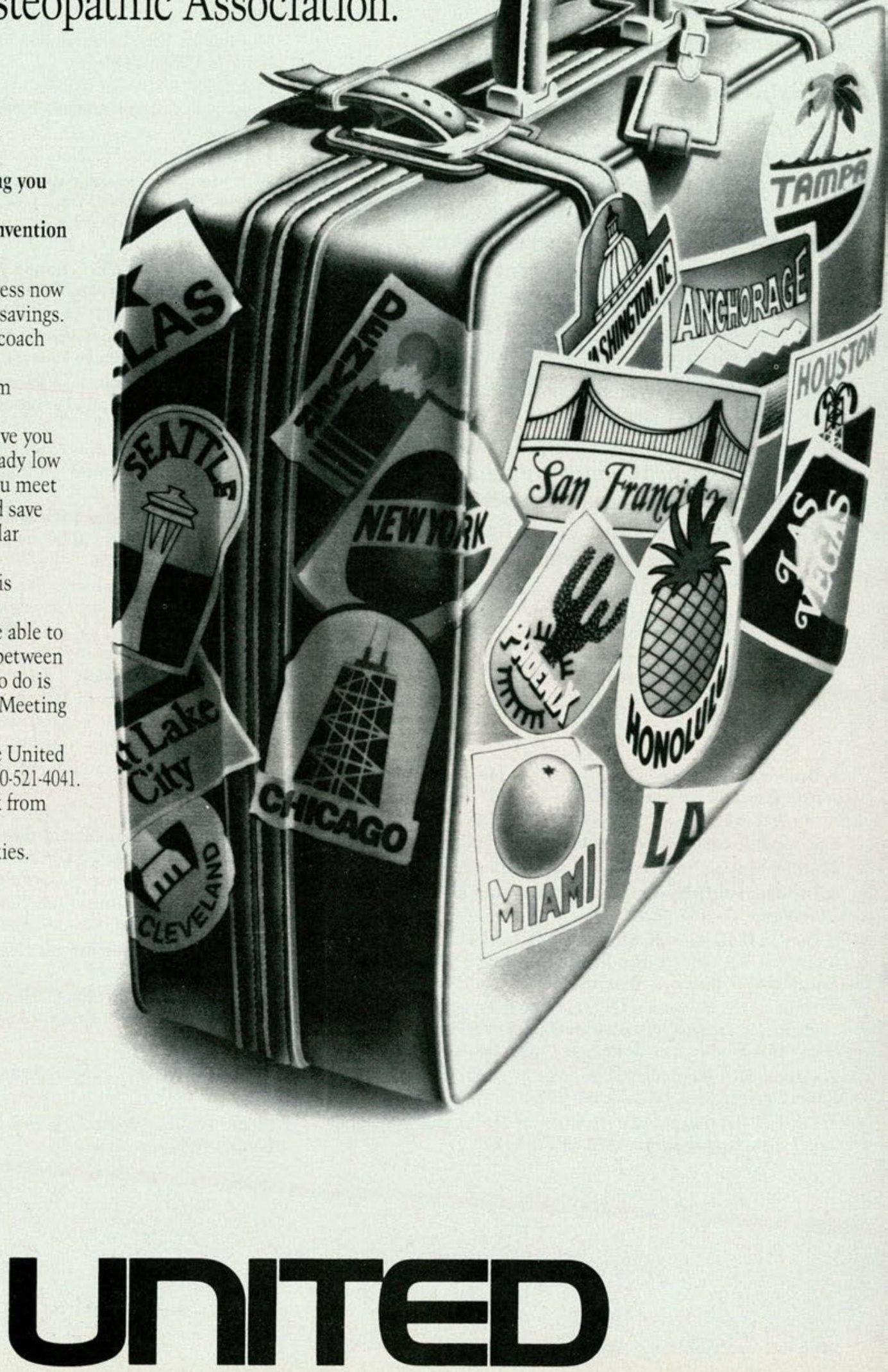



\section{(a)1 \\ A BRIGHT IDEA.. IN MILD TO MODERATE HYPERTENSION}

180-mg Calan SR...once-daily, single-agent therapy

- Efficacy proven comparable to 240 mg $^{1}$

- 24-hour control with-once-daily dosing*

- Low-dose, well-tolerated therapy ${ }^{1}$

A more economical choice ${ }^{\ddagger}$

-Total daily dosages above $240 \mathrm{mg}$ should be administered in divided doses. Calan SR should be administered with food

constipation, which is easily managed in most patients, is the most commonly reported side effect of Calan SR

'Price comparison versus 240-mg Calan SR.

Please see next page of this advertisement for references and a brief summary of prescribing information.

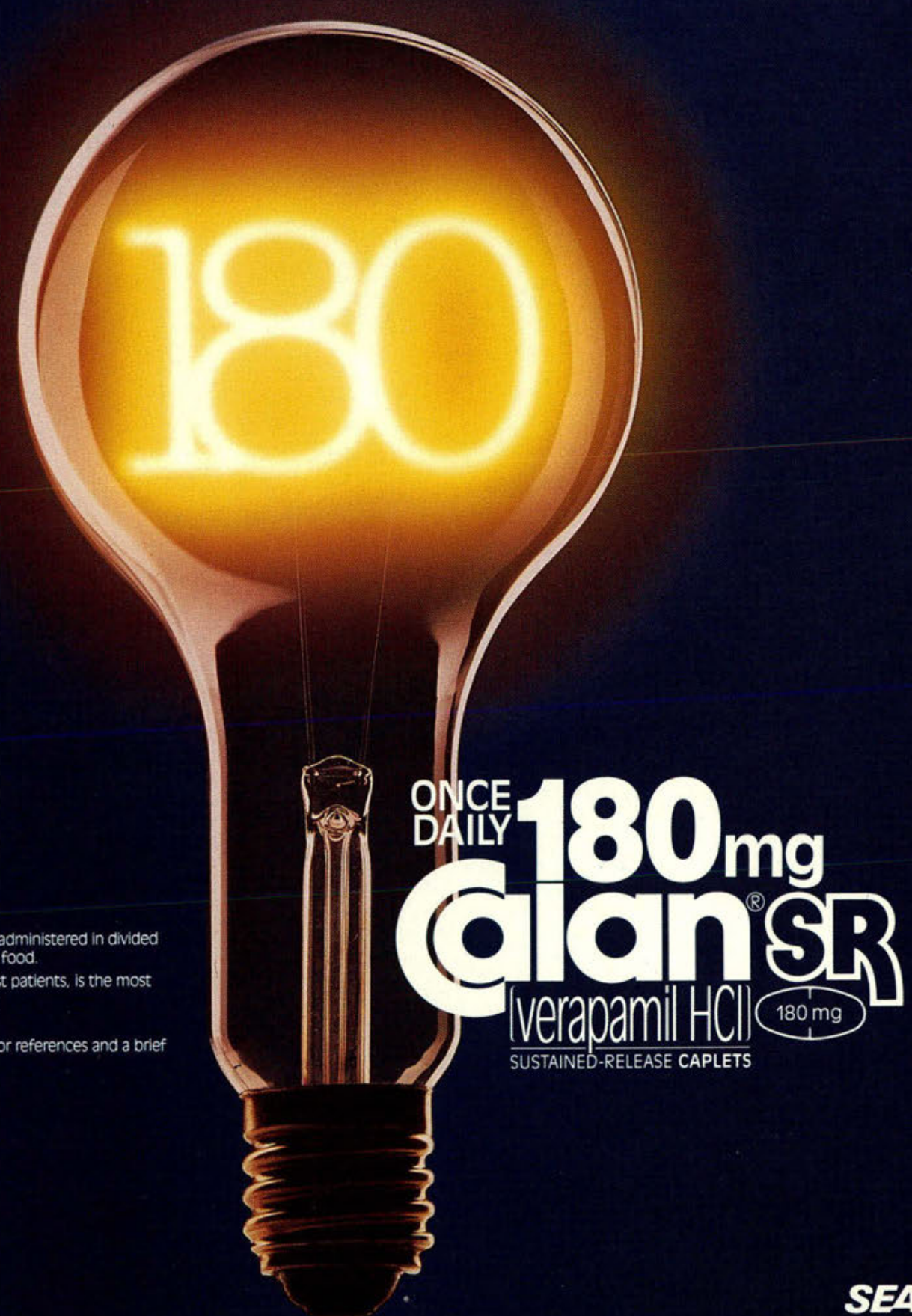




\section{Consistent with 1988 JNC recommendation...}

\section{The 1988 report of the Joint National Committee on Detection, Evaluation, and Treatment of High Blood Pressure recommends that blood pressure be controlled "...with the fewest drugs at their lowest dose...."}

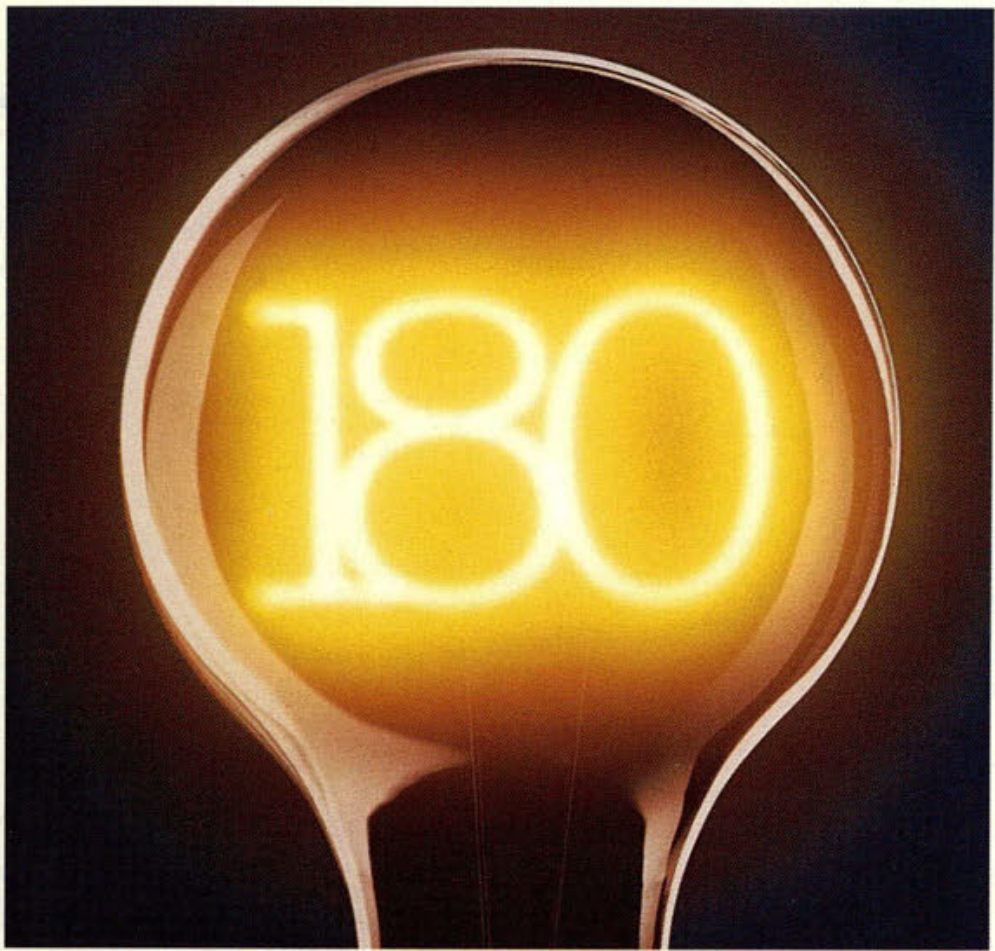

\section{When you want high single-agent efficacy in a lower dose, prescribe...}

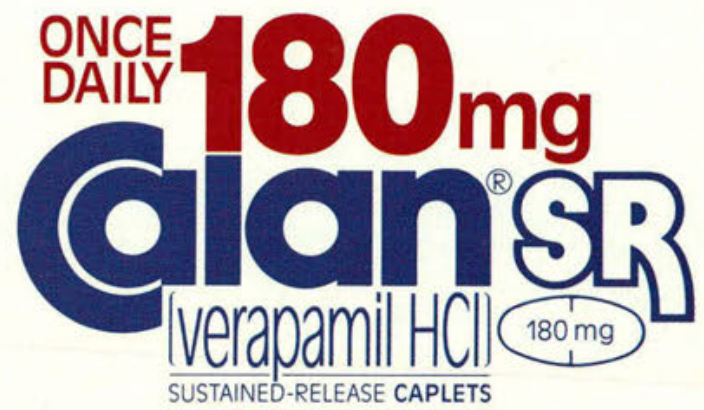

A BRIGHT IDEA in verapamil SR therapy

\section{References:}

1. Data on file, G.D. Searle \& Co. 2. 1988 Joint National Committee:

The 1988 report of the Joint National Committee on Detection,

Evaluation, and Treatment of High Blood Pressure. Arch Intern Med

1988;148:1023-1038

\section{BRIEF SUMMARY}

Contraindications: Severe LV dysfunction (see Warnings), hypotension (systolic pressure $<90 \mathrm{~mm} \mathrm{Hg}$ ) or cardiogenic shock, sick sinus syndrome (if no pacemaker is present), 2nd- or 3rd-degree AV block (if no pacemaker is present), atrial flutter/fibrillation with an accessory bypass tract (eg, WPW or LGL syndromes), hypersensitivity to verapamil.

Warnings: Verapamil should be avoided in patients with severe LV dysfunction leg, ejection fraction $<30 \%$ ) or moderate to severe symptoms of cardiac failure and in patients with any degree of ventricular dysfunction if they are receiving a beta-blocker. Control milder heart failure with optimum digitalization and/or diuretics before Calan SR is used. Verapamil may occasionally produce hypotension. Elevations of liver enzymes have been reported. Several cases have been demonstrated to be produced by verapamil. Periodic monitoring of liver function in patients on verapamil is prudent. Some patients with paroxysmal and/or chronic atrial flutter/fibrillation and an accessory AV pathway (eg. WPW or LGL syndromes) have developed an increased antegrade conduction across the accessory pathway bypassing the AV node, producing a very rapid ventricular response or ventricular fibrillation after receiving I.V. verapamil (or digitalis). Because of this risk, oral verapamil is contraindicated in such patients. AV block may occur (2nd-and 3 rd-degree, $0.8 \%$ ). Development of marked 1st-degree block or progression to 2 nd- or 3rddegree block requires reduction in dosage or, rarely, discontinuation and institution of appropriate therapy. Sinus bradycardia, 2nd-degree AV block, sinus arrest, pulmonary edema and/or severe hypotension were seen in some critically ill patients with hypertrophic cardiomyopathy who were treated with verapamil.

Precautions: Verapamil should be given cautiously to patients with impaired hepatic function (in severe dysfunction use about $30 \%$ of the normal dose) or impaired renal function, and patients should be monitored for abnormal prolongation of the PR interval or other signs of overdosage. Verapamil may decrease neuromuscular transmission in patients with Duchenne's muscular dystrophy and may prolong recovery from the neuromuscular blocking agent vecuronium. It may be necessary to decrease verapamil dosage in patients with attenuated neuromuscular transmission. Combined therapy with beta-adrenergic blockers and verapamil may result in additive negative effects on heart rate, atrioventricular conduction and/or cardiac contractility; there have been reports of excessive bradycardia and AV block, including complete heart block. The risks of such combined therapy may outweigh the benefits. The combination should be used only with caution and close monitoring. Decreased metoprolol clearance may occur with combined use. Chronic verapamil treatment can increase serum digoxin levels by $50 \%$ to $75 \%$ during the first week of therapy, which can result in digitalis toxicity. In patients with hepatic cirrhosis, verapamil may reduce total body clearance and extrarenal clearance of digitoxin. The digoxin dose should be reduced when verapamil is given, and the patient carefully monitored. Verapamil will usually have an additive effect in patients receiving blood-pressure-lowering agents. Disopyramide should not be given within 48 hours before or 24 hours after verapamil administration.
Concomitant use of flecainide and verapamil may have additive effects on myocardial contractility AV conduction, and repolarization. Combined verapamil and quinidine therapy in patients with hypertrophic cardiomyopathy should be avoided, since significant hypotension may result. Concomitant use of lithium and verapamil may result in a lowering of serum lithium levels or increased sensitivity to lithium. Patients receiving both drugs must be monitored carefully Verapamil may increase carbamazepine concentrations during combined use. Rifampin may reduce verapamil bioavailability. Phenobarbital may increase verapamil clearance. Verapamil may increase serum levels of cyclosporin. Concomitant use of inhalation anesthetics and calcium antagonists needs careful titration to avoid excessive cardiovascular depression. Verapamil may potentiate the activity of neuromuscular blocking agents (curare-like and depolarizing); dosage reduction may be required. Adequate animal carcinogenicity studies have not been performed. One study in rats did not suggest a tumorigenic potential, and verapamil was not mutagenic in the Ames test. Pregnancy Category $\mathrm{C}$. There are no adequate and well-controlled studies in pregnant women. This drug should be used during pregnancy, labor, and delivery only if clearly needed. Verapamil is excreted in breast milk; therefore, nursing should be discontinued during verapamil use.

Adverse Reactions: Constipation (7.3\%), dizziness (3.3\%), nausea $(2.7 \%)$, hypotension (2.5\%), headache $(2.2 \%)$, edema (1.9\%), CHF, pulmonary edema (1.8\%), fatigue $(1.7 \%)$, dyspnea $(1.4 \%)$, bradycardia: HR $<50 /$ min $(1.4 \%)$, AV block: total $1^{\circ}, 2^{\circ}, 3^{\circ}(1.2 \%), 2^{\circ}$ and $3^{\circ}(0.8 \%)$, rash $(1.2 \%)$, flushing $(0.6 \%)$, elevated liver enzymes. The following reactions, reported in $1.0 \%$ or less of patients, occurred under conditions where a causal relationship is uncertain: angina pectoris, atrioventricular dissociation, chest pain, claudication, myocardial infarction, palpitations, purpura (vasculitis), syncope, diarrhea, dry mouth, gastrointestinal distress, gingival hyperplasia, ecchymosis or bruising, cerebrovascular accident, confusion, equilibrium disorders, insomnia, muscle cramps, paresthesia, psychotic symptoms, shakiness, somnolence, arthralgia and rash, exanthema, hair loss, hyperkeratosis, macules, sweating, urticaria, Stevens-Johnson syndrome, erythema multiforme, blurred vision, gynecomastia, increased urination, spotty menstruation, impotence.

\section{SELLE $\begin{aligned} & \text { G.D. Searle \& Co. } \\ & \text { Box 5110, Chicago, IL } 60680\end{aligned}$}

Address medical inquiries to:

G.D. Searle \& Co.

Medical \& Scientific

Information Department

4901 Searle Parkway

Skokje, IL 60077 
